Tero $L A H D E$

Ricardo SUAREZ-BERTOA

Michael CLAIROTTE

Theodoros GRIGORATOS

Alessandro ZARDINI

Adolfo PERUJO

Giorgio MARTINI

\title{
Particle number measurements in the European legislation and future JRC activities
}

The solid particle number method was introduced in the European Union (EU) light-duty legislation for diesel vehicles to ensure the installation of the best-available technology for particles (i.e., wall-flow diesel particulate filters) without the uncertainties of the volatile nucleation mode and without the need of large investment for purchasing the equipment. Later it was extended to gasoline vehicles with direct injection engines, heavy-duty engines (both compression ignition and positive ignitions) and non-road mobile machinery engines. Real Driving Emissions (RDE) testing on the road with Portable Emissions Measurement Systems (PEMS) for particle number (and $N O_{x}$ ) during type approval and in-service conformity testing was recently (in 2017) introduced for light-duty vehicles, and is under discussion for heavy-duty vehicles in-service conformity testing.

This paper will summarize the existing legislation regarding solid particle number and discuss the on-going activities at EU level. The main focus at the moment is on improving the calibration procedures, and extending the lower detection size below $23 \mathrm{~nm}$ with interlaboratory exercises. In parallel, discussions are on-going to introduce testing at low ambient temperature, regeneration emissions in the light-duty regulation, a particle limit for other technologies such as gasoline port-fuel injection vehicles, and the feasibility of particle measurements to L-category vehicles (mopeds, motorcycles, tricycles and minicars). A short overview of periodical technical inspection investigations and the situation regarding non-exhaust traffic related sources with special focus on brakes and tyres will be described.

Key words: vehicle emissions regulation, particle measurement programme (PMP), portable emission measurement systems (PEMS), real driving emissions (RDE), periodical technical inspection, particle number, sub-23 $\mathrm{nm}$

\section{Introduction}

Ultrafine particles (smaller than $0.1 \mu \mathrm{m}$ ) have been associated with adverse health effects and act through mechanisms not shared with larger particles [1]. Road traffic contributes significantly to Particle Number (PN) concentrations and can reach $90 \%$ in busy roads [2].

At the beginning of the 90's the Particulate Matter (PM) emissions were regulated for light-duty vehicles in the European Union (EU) by weighing the mass collected on filters before and after a prescribed test cycle (speed profile). However, since early 2000, the gravimetric method was not sensitive enough to accurately determine the PM emissions of vehicles equipped with Diesel Particulate Filter (DPF). The possibility to develop a more sensitive and accurate methodology that would replace or complement the regulated gravimetric procedure, requiring low investment costs, was the objective of the Particle Measurement Program (PMP). The final decided method was based upon counting solid (non-volatile) particles larger than $23 \mathrm{~nm}$ [3]. A minimum diameter of $23 \mathrm{~nm}$ size was selected in order to include the smallest soot particles and exclude volatile nucleation mode particles. Volatile particles were excluded in order to improve the repeatability and reproducibility of the method to levels acceptable for legislative purposes [4]. The PMP working group had no medical expertise and did not seek to pre-judge the advice from medical experts with respect to the most crucial particle characteristics affecting human health. The new method was introduced to ensure the installation of the bestavailable technology for particles (i.e., wall-flow DPFs) without the uncertainties of the volatile nucleation mode and without the need of large investment for purchasing the equipment. Furthermore, the particle counting method did not replace but rather complemented the gravimetric procedure that is still in force.

The PMP group activities stopped at the end of 2011 with the introduction of the Solid Particle Number $>23 \mathrm{~nm}$ (SPN23) method in the light-duty and heavy-duty European regulations. In $2013 \mathrm{EU}$ and Switzerland requested further investigation of particle number emissions from spark ignition engines. There were also concerns regarding the existence of sub- $23 \mathrm{~nm}$ particles. The new Terms of Reference included the following topics [5]:

- Engine dyno raw exhaust SPN measurements for heavyduty at type approval

- Emissions during regeneration events

- Emissions from Gasoline Direct Injection (GDI) vehicles

- Development of SPN equipment to measure below $23 \mathrm{~nm}$

- Calibration procedures update (and if necessary for lower size)

- Non-exhaust particle emissions

The EU vehicle emissions legislation is the only one that controls SPN23 emissions, with the exception of the recently introduced China $5 \& 6$ limits. Since the introduction of the first SPN limit in 2011 (Euro 5b) for diesel vehicles the progress has been very fast. The first review on the SPN23 regulation in 2012 summarized the PMP activities until the introduction of the SPN23 limits in the light-duty and heavy-duty emissions regulations [4]. A later review summarised the European SPN23 legislations [6]. Other reviews summarised the instrumentation typically used for particle measurements $[7,8]$. 
Particle number measurements in the European legislation and future JRC activities

Table 1. Overview of European regulations regarding PM and SPN23 for light-duty, heavy-duty, NRMM and L-category vehicles. Status 2018

\begin{tabular}{|c|c|c|c|c|}
\hline & Regulation & Cycle & PM [mg/km or mg/kWh] & SPN23 [p/km or p/kWh] \\
\hline \multicolumn{5}{|c|}{ Light-duty (Euro 6) } \\
\hline Type approval & $\begin{array}{l}2017 / 1151 \\
2017 / 1154\end{array}$ & $\begin{array}{l}\text { WLTC } \\
\text { On-road (RDE) }\end{array}$ & 4.5 & $\begin{array}{c}6 \times 10^{11} \\
\mathrm{CF}=1.5\end{array}$ \\
\hline ISC & $\begin{array}{l}\text { To be adopted end } \\
2018\end{array}$ & $\begin{array}{l}\text { WLTC } \\
\text { On-road (RDE) }\end{array}$ & - & $\begin{array}{c}6 \times 10^{11} \\
\mathrm{CF}=1.5\end{array}$ \\
\hline \multicolumn{5}{|c|}{ Heavy-duty (Euro VI) } \\
\hline Type approval & $582 / 2011$ & $\begin{array}{l}\text { WHTC } \\
\text { WHSC }\end{array}$ & $\begin{array}{l}10 \\
10\end{array}$ & $\begin{array}{l}6 \times 10^{11} \\
8 \times 10^{11}\end{array}$ \\
\hline ISC & & On-road & - & $\mathrm{CF}=1.63(\mathrm{tbc})$ \\
\hline \multicolumn{5}{|c|}{ NRMM (Stage V) } \\
\hline Type approval & $\begin{array}{l}2017 / 654 \\
2016 / 1628\end{array}$ & $\begin{array}{l}\text { NRTC } \\
\text { NRSC }\end{array}$ & 15 & $1 \times 10^{12}$ \\
\hline ISC (monitoring) & & & - & - \\
\hline \multicolumn{5}{|c|}{ L-category (Euro 5 from 2020) } \\
\hline Type approval & $2013 / 168$ & WMTC & $4.5($ diesel/GDI $)$ & - \\
\hline
\end{tabular}

However, since these reviews, and especially in 2017, many changes took place. The objective of this paper is to briefly update on the current status and near future activities regarding the SPN regulation. The focus is the EU legislation and in particular activities of the Joint Research Centre (JRC) of the European Commission.

\section{SPN23 legislation in EU}

An overview of current regulations regarding SPN23 emissions is given below and presented in Table 1.

\subsection{EU and UNECE}

In the framework of the United Nations' Economic Commission for Europe (UNECE) in Geneva, WP.29 (World Forum for Harmonization of Vehicle Regulations) and its subsidiary bodies are developing the Regulations under the 1958 Agreement in cooperation with all Contracting Parties to the Agreement and non-governmental organizations (NGOs). United Nations (UN) Regulations are not applicable on a mandatory basis, but if a Contracting Party decides to apply a UN Regulation, the adoption becomes a binding act.

The WP.29 and the European Commission are currently working on the harmonization between UN Regulations and EU Directives or Regulations. Currently, some of the EU Directives or Regulations are technically equivalent to UN Regulations or only refer to the requirements of the corresponding UN Regulation.

The UN Global Technical Regulations (GTRs) are the technical regulations being established under the 1998 Agreement and do not refer to a type approval or certification procedure as mentioned in the EU Directives or UN Regulations. The main reason is that the process of selfcertification used in the United States is incompatible with the type approval. The UN Regulations are considered candidates for the elaboration of UN GTRs.

\subsection{Light-duty vehicles}

The EU emissions regulation requires, in addition to PM mass, the measurement of Solid Particle Number $>23 \mathrm{~nm}$ (SPN23) for type approval of diesel light-duty vehicles

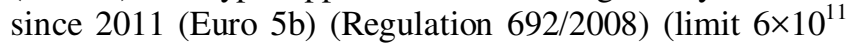
$\mathrm{p} / \mathrm{km}$ ), and for Gasoline Direct Injection (GDI) light-duty vehicles since 2014 (Euro 6) (Regulation 459/2012) (limit $6 \times 10^{12} \mathrm{p} / \mathrm{km}$ and $6 \times 10^{11} \mathrm{p} / \mathrm{km}$ after 2017). Regulation 2017/1151 repealed Regulation 692/2008 and introduced a new test cycle (WLTC). In addition, Real Driving Emissions (RDE) testing on the road with Portable Emissions Measurement Systems (PEMS) for SPN23 and $\mathrm{NO}_{\mathrm{x}}$ during type approval (Regulation 2016/427) and in-service conformity testing (RDE 4th package) were introduced in 2017, where: from 2017 (Euro 6d Temp) a CF of 1.5 for SPN23 (Regulation 2017/1154) and 2.1 (Regulation 2016/646) for $\mathrm{NO}_{\mathrm{x}}$ applies and from 2020 the $\mathrm{CF}$ of $\mathrm{NO}_{\mathrm{x}}$ will be reduced to 1.5 (Euro $6 \mathrm{~d}$ ). The CFs are under annual revision. The first 2017 revision decreased the $\mathrm{NO}_{\mathrm{x}} \mathrm{CF}$ to 1.43 [9]. The test procedure and the test cycle are described in 2017/1151, of which Annex XXI is basically UNECE GTR No. 15.

\subsection{Heavy-duty engines/vehicles}

The type approval of an engine is conducted on an engine dynamometer with a cold start and a hot start transient cycle and a steady cycle. The SPN23 limit for heavy-duty engines was introduced in 2013 (Euro VI) for compression ignition (diesel) engines (Regulation 582/2011) and in 2014 for positive ignition engines (Regulation 133/2014). The limit is $6 \times 10^{11} \mathrm{p} / \mathrm{kWh}$ for the transient cycle (weighing $14 \%$ the cold start cycle and $86 \%$ the hot start cycle) and $8 \times 10^{11}$ $\mathrm{p} / \mathrm{kWh}$ for the steady cycle. The SPN23 measurement procedure (Regulation 64/2012, UNECE Regulation 49) is almost identical to the light-duty vehicles procedure. The relevant GTR is UNECE GTR No. 4.

Since Euro VI the in-service conformity (ISC) testing of a heavy-duty engine is conducted on the road over normal driving patterns, conditions and payloads using PEMS (Regulation 582/2011). The testing is conducted over a mix of urban $(50 \mathrm{~km} / \mathrm{h})$, rural, and motorway (highway) (> 75 $\mathrm{km} / \mathrm{h}$ ) conditions, with exact percentages of these conditions depending on vehicle category (Regulation 2016/ 1718). The first in-use test should be conducted at the time of type approval testing and the result should be lower than the Euro VI limit corrected with a conformity factor (1.5 for gaseous pollutants) that takes into account the PEMS measurement uncertainty and the test-to-test variability. The PEMS testing is currently applicable only to gaseous pollutants. After a long evaluation of the PM mass method with PEMS [10], in 2015 it was decided to evaluate the SPN23 method. The evaluations at JRC [11] and OEMs [12] were promising and the ISC SPN23 PEMS method will be introduced in the next years. 


\subsection{Non-Road Mobile Machinery (NRMM)}

Regulation 2016/1628 repealed Directive 97/68/EC in 2016 and introduced SPN23 limits to non-road engines $(19-560 \mathrm{~kW})$, inland waterway vessels (> $300 \mathrm{~kW})$, and rail traction engines in 2017. The procedures and test cycles (NRSC and NRTC) are described in Regulation 2017/654. The 05 series of amendments updates UNECE Regulation No. 96, based on the European regulation. The relevant GTR is GTR No. 11.

In service monitoring (no conformity factor) is applicable to 56-560 kW engines (Regulation 2017/655) with PEMS, but only for gaseous pollutants. A near future amendment will include $19-56 \mathrm{~kW}$ engines and above 560 $\mathrm{kW}$, while $<19 \mathrm{~kW}$ engines are currently under a feasibility study by JRC.

In addition to the type approval SPN23 limits, Swiss Regulation SR 941.242 (published in 2015) mandates the in-use compliance testing of all construction machinery DPFs, bi-annually starting from 2017 (SPN23 limit 250000 $\mathrm{p} / \mathrm{cm}^{3}$ at high idle).

\subsection{L-category vehicles}

Regulation (EU) 168/2013 provides the details of a revised vehicle classification together with the provisions for approval and market surveillance of L-category vehicles at Euro 4 (from 2016) and Euro 5 levels (from 2020). PM measurements were introduced at Euro 4 level with a lenient limit of $80 \mathrm{mg} / \mathrm{km}$ required for compression ignition (diesel) and gasoline direct injection (GDI) engines mounted on motorcycles, tricycles and minicars. A more stringent limit value of $4.5 \mathrm{mg} / \mathrm{km}$ is set at Euro 5 level for all subcategories with GDI and compression ignition engines. No provisions on SPN23 were introduced. UNECE Regulation No. 40 (motorcycles) and UNECE Regulation No. 47 (mopeds) are outdated. The current GTR No. 2 does not contain SPN23 provisions either, but only PM and it is under revision by the relevant group within the UNECE (GRPE).

Article 23 of the Regulation 168/2013, mandated an environmental effect study to provide additional underpinning of the Euro 5 step through modelling, technical feasibility, and cost effectiveness analysis. JRC performed a Preparatory work phase [13] and Phase 1 [14] of this environmental effect study with the objectives to take stock of fleet and structure of the L-category vehicle sector, perform relevant data-mining, and to prepare the technical approach. The preparatory work showed that L-category vehicles can have high SPN emissions with a high percentage of them not counted by the current SPN23 protocol. However, it was argued that decreasing the lower detectable size could result in artefacts and more research was therefore considered necessary [15].

The final environmental study [16] concluded that introducing specific SPN23 limits for any L-category vehicles would first require better understanding of the emissions performance of such vehicles, as new emission control technologies at Euro 5 step become available. SPN emissions from L-category vehicles are mostly linked to lube oil consumption and upcoming stringent hydrocarbons limits at Euro 5 may be proven effective to control SPN emissions from such vehicles as well, without the need of mandating a separate SPN standard [16].

\subsection{Other}

Periodic Technical Inspection (PTI): Directive 2014/45/EU repealed Directive 2009/40/EC and includes only smoke (opacity) test for diesel vehicles. In general, there is no correlation between $\mathrm{PM} / \mathrm{PN}$ emissions and smoke.

On-Board Diagnostics (OBD): There is only a PM limit for OBD (12 mg/km for light-duty vehicles and $25 \mathrm{mg} / \mathrm{km}$ for heavy-duty). NRMM do not have OBD requirements.

Low (ambient) temperature test (Type 6): Regulation 2017/1151 refers to UNECE Regulation 83. There is no PM or SPN limit.

\section{PMP current activities}

The following sections will summarise the progress on the topics that PMP deals with. Most topics relate to lightduty and heavy-duty vehicles. Nevertheless they are applicable to other vehicle categories as well.

\subsection{Volatile Particle Remover (VPR) calibration}

SPN23 systems consist of a Volatile Particle Remover (VPR), that dilutes the sample and removes volatiles, and a Condensation Particle Counter (CPC) that counts particles $>23 \mathrm{~nm}$ [4]. There are some concerns with respect to the accuracy of the instrument calibrations, and accordingly the comparability of results obtained using different commercial systems. A VPR inter-laboratory correlation study was launched in 2011 aiming at the assessment of the different VPR calibration procedures established by the different manufacturers. The "golden" VPR was a prototype two stage ejector system with an intermediate evaporation tube. The "golden" Aerosol Generator was a graphite spark generator. The "golden" instrumentation also included a CPC [17].

The average Particle Number Concentration Reduction Factor (PCRF) at 30, 50 and $100 \mathrm{~nm}$ values determined at eight of the total eleven laboratories using the golden instrumentation agreed within $\pm 5 \%$, but three laboratories measured systematically higher values $(10 \%, 20 \%$ and $40 \%$, respectively) (Fig. 1). This overestimation was most probably related to a backpressure build-up at the exit of the second ejector, as verified in the lab with the highest overestimation.

The graphite particles produced from the Golden aerosol generator were found to be thermally stable. However, they were highly charged and when not neutralized, the size classified particles contained a large fraction of larger particles. On the other hand, thermally treated $30 \mathrm{~nm}$ particles of diffusion flame soot generators CAST (Combustion Aerosol Standard) still shrunk in the VPRs. It was recommended that a low cut-off size CPC is employed when CAST or $\mathrm{NaCl}$ particles are employed in PCRF calibrations.

The inter-laboratory exercise also showed that an accurate calibration of the VPR with polydisperse aerosol (using SMPS) was difficult and required that the concentration was at levels that would freeze coagulation.

At PMP meetings the VPR calibration topics were discussed and the following conclusions were taken in order to reduce the permitted flexibilities [18]: 


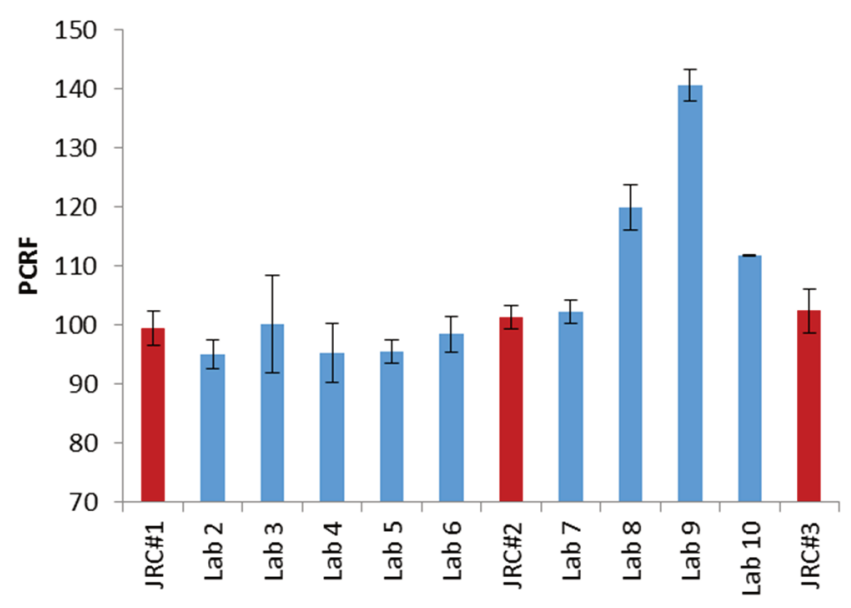

Fig. 1. Average Particle number Concentration Reduction Factors (PCRF) at 30,50 and $100 \mathrm{~nm}$ graphite particles with the Golden aerosol generator and the Golden CPC at different laboratories [17]

- The reference CPC should have counting efficiency at $23 \mathrm{~nm}>90 \%$. It should be also calibrated for linearity.

- When the two CPCs method is used for calibration of VPRs, the two CPCs should be inter-calibrated.

- The stability of the aerosol during the VPR calibration should be improved from $10 \%$ to $5 \%$.

- For the polydisperse validation a Count Median Diameter (CMD) and a Geometric Standard Deviation (GSD) should be defined. At the moment the suggestion is 45$55 \mathrm{~nm}$ and 1.6-1.8.

- The tetracontane requirements are easy to pass and a polydisperse test should be added: $1 \mathrm{mg} / \mathrm{m}^{3}$ of alkane or emery oil is the suggestion.

\subsection{CPC calibration}

The legislation does not define a calibration aerosol for CPCs and studies have shown that it has an influence on the counting efficiencies [19]. An inter-laboratory calibration exercise for engine exhaust CPCs was launched in 2016 to assess the repeatability and reproducibility of soot-like aerosols. During this exercise, three CPCs and one soot generator were circulated among 7 laboratories in Europe. The circulated instruments were compared with in-house reference counters and in-house spark-discharge soot, diffusion flame soot, silver nucleation and emery oil generators [21].

Figure 2 summarises the results. At the plateau region there was no significant difference between aerosols. At 70 $\mathrm{nm}$ the CPC efficiency was $2-3 \%$ below its maximum counting efficiency with soot-like aerosol, while with emery oil even at $55 \mathrm{~nm}$ the efficiency was maximum. At 23 $\mathrm{nm}$ the soot-like aerosol average counting efficiency was between $27.0 \%$ and $32.0 \%$, while emery oil averaged $49.3 \%$. At $41 \mathrm{~nm}$ the soot efficiencies were between $77.2 \%$ and $79.7 \%$, while with emery oil $91.5 \%$. The variance among in-house soot generators was on the same level as emery oil (3.1 percentage points at $55 / 70 \mathrm{~nm}$ ) at all particle sizes; however, the variability with emery oil was due to a drift of the CPC. The main conclusion was that soot-like aerosol from diffusion flame and spark-discharge generators is a suitable candidate for the harmonization of particle number calibrations in automotive exhaust applications; however, there are still concerns whether it can reach the same levels of accuracy as the emery oil.

Interestingly, only half of the laboratories calibrated the circulating $10 \mathrm{~nm} \mathrm{CPC}$, indicating that the calibration at that size with soot-like particles is more challenging.

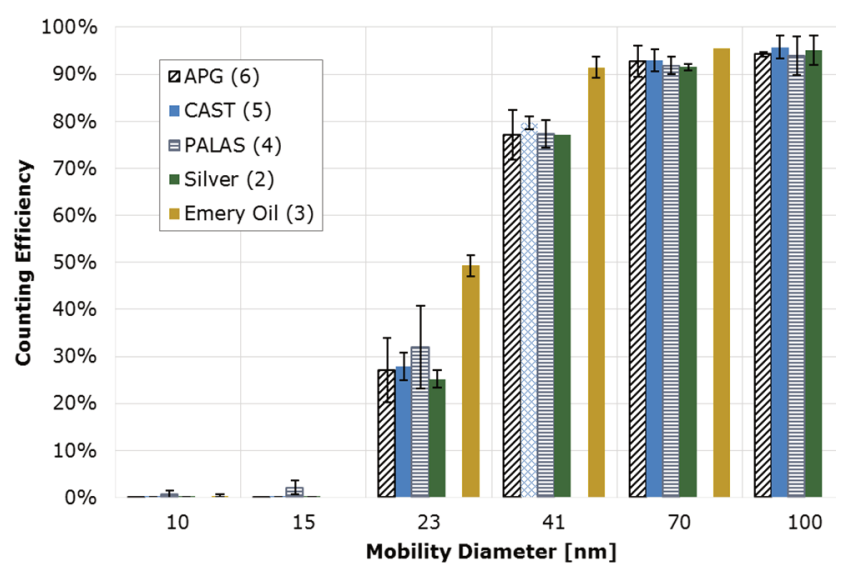

Fig. 2. Calibration results of the golden CPC with various particle generators across Europe. Number in brackets indicates number of laboratories

[21]. APG = AVL Particle Generator (thermally stable CAST)

At PMP meetings the CPC calibration topics were discussed and the following conclusions were taken to reduce the permitted flexibilities [18]:

- The reference CPC should be calibrated according to ISO 27891.

- The slope should remain 0.9 to 1.1 , but the residuals check should be reduced to $\pm 4 \%$ (from the slope).

- The CPC slope calibration $\mathrm{k}$ factor should be included (and reported).

- The ISO 27891 should be adopted with application notes when some parts are not applicable.

At the moment the prevalent view is that the calibration material should be soot-like and other materials should be adjusted to soot.

\subsection{Regeneration}

The emissions during regeneration events are taken into account by weighing the final emissions with the emissions during regeneration events and the regeneration frequency. At the moment this applies to heavy-duty and NRMM, but not to light-duty vehicles. The main reason is that during the PMP investigations and the light-duty inter-laboratory correlation exercise, it was found that the contribution of the regeneration emissions was negligible [21]. However, later studies showed that is not necessarily true for other more aggressive cycles including prolonged operation at motorway driving conditions [22]. The SPN23 emissions during phases with regeneration can exceed many times the Euro 5b PN limit. Subsequently, DPF sizes, filtration characteristics and material options have evolved, and more complex $\mathrm{NO}_{\mathrm{x}}$ and $\mathrm{PN}$ aftertreatment combinations are being employed. PMP investigated whether these changes require modifications to the regulatory procedure to adequately measure particles from regenerations [23], and whether there are any particular issues not to include regeneration in light-duty legislation. 
Figure 3 (upper panel) shows the emissions of a vehicle during a regeneration event, measured with various instruments connected to the dilution tunnel (CVS). The total PN concentration (including volatiles), as measured by an Engine Exhaust Particle Sizer (EEPS) $>6 \mathrm{~nm}$ exceed $10^{7}$ $\mathrm{p} / \mathrm{cm}^{3}$. The SPN23 concentration is around $10^{4} \mathrm{p} / \mathrm{cm}^{3}$, while SPN10 reaches $10^{6} \mathrm{p} / \mathrm{cm}^{3}$ at the beginning of the regeneration and stabilises at $10^{4} \mathrm{p} / \mathrm{cm}^{3}$ after $10 \mathrm{~min}$. The SPN3 concentration is much higher for the whole regeneration event. It is important to note the robustness of the PMP protocol: The SPN23, SPN10, SPN3 emissions are not affected by a 10 times change of the PCRF (200 to 2000) during the test. Additionally, another system with catalytic stripper and a $10 \mathrm{~nm}$ CPC measured similarly with the PMP system and a $10 \mathrm{~nm}$ CPC (within experimental uncertainties and particle losses corrections). What is interesting though is that when the test was repeated with some instruments connected to the tailpipe (no instruments available at the CVS), the high sub-23 nm particles were not seen (Fig. 3 lower panel). For this test the accumulated soot/material was less.

The main conclusion is that the PMP methodology is robust enough to measure emissions during regeneration events (note that a PCRF of 1000 is recommended) [24]. The conclusion applies also to $10 \mathrm{~nm}$ measurements, although some concerns were raised for formation of "nonvolatile" particles due to desorption of material from the vehicle or the tube between the vehicle and the CVS due to the high exhaust gas temperatures. Thus, it is important to properly precondition the vehicle and facilities before regeneration tests, in order to ensure minimum contribution from previous vehicles.
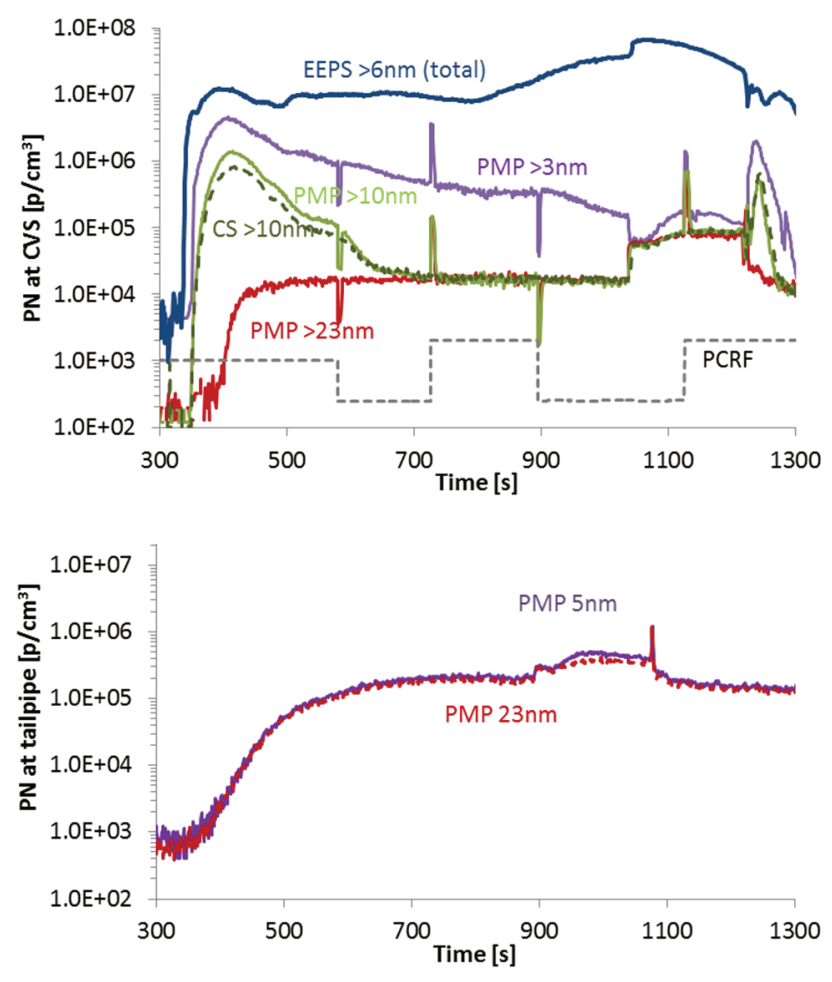

Fig. 3. PN emissions during triggered/forced regeneration with the vehicle parked. Upper panel: Measurements from the CVS. Lower panel: Measurements from the tailpipe (subsequent test) [25]
The emissions during regeneration events are taken into account by the $\mathrm{K}_{\mathrm{i}}$ factor ( $\mathrm{i}=\mathrm{SPN} 23$ in this case):

$$
\mathrm{M}_{\mathrm{pi}}=\left(\mathrm{M}_{\mathrm{si}} \mathrm{D}+\mathrm{M}_{\mathrm{ri}} \mathrm{d}\right) /(\mathrm{D}+\mathrm{d})
$$

where: $\mathbf{M}_{\mathrm{si}}$ are the mean emissions of compound $\mathrm{i}$ without regeneration $(\mathrm{p} / \mathrm{km}), \mathrm{M}_{\mathrm{ri}}$ are the mean emissions of compound i during regeneration $(\mathrm{p} / \mathrm{km}), \mathrm{M}_{\mathrm{pi}}$ are the mean emissions of compound $\mathrm{i}(\mathrm{p} / \mathrm{km}), \mathrm{d}$ is the number of complete applicable test cycles required for regeneration, $\mathrm{D}$ is the number of complete applicable test cycles between two cycles where regeneration events occur.

$$
\begin{gathered}
\mathrm{K}_{\mathrm{i}}(\text { factor })=\mathrm{M}_{\mathrm{pi}} / \mathrm{M}_{\mathrm{si}} \\
\mathrm{K}_{\mathrm{i}} \text { (offset) }=\mathrm{M}_{\mathrm{pi}}-\mathrm{M}_{\mathrm{si}}
\end{gathered}
$$

The $\mathrm{K}_{\mathrm{i}}$ factor is not included in the light-duty regulation and there is no information in the literature about SPN. Table 2 summarises the results of the PMP Golden vehicle [21], presented data [26] and a few more internal JRC data. The followed procedure was not exactly the one prescribed in the regulation (continuous cycles until regeneration). Between regeneration events different cycles were conducted (even on road tests), thus the $\mathrm{K}_{\mathrm{i}}$ factors are approximations, but nevertheless realistic. No vehicle exceeds the SPN23 limit even when considering the regeneration events. However, there are vehicles that remain more than one order of magnitude below the SPN23 limit, and others that are close to the limit. The range of the $K_{i}$ factors (0-91) or offset $\left(0-4.9 \times 10^{11} \mathrm{p} / \mathrm{km}\right)$ is very wide.

\begin{tabular}{|c|c|c|c|c|c|c|c|}
\hline Vehicle & $\begin{array}{c}\mathrm{M}_{\mathrm{si}} \\
{[\mathrm{p} / \mathrm{km}]}\end{array}$ & $\begin{array}{c}\mathrm{D} \\
{[\mathrm{km}]}\end{array}$ & $\begin{array}{c}\mathrm{M}_{\mathrm{ri}} \\
{[\mathrm{p} / \mathrm{km}]}\end{array}$ & $\begin{array}{c}\mathrm{D} \\
{[\mathrm{km}]}\end{array}$ & $\begin{array}{c}\mathrm{M}_{\mathrm{pi}} \\
{[\mathrm{p} / \mathrm{km}]}\end{array}$ & $\mathrm{K}_{\mathrm{i}}$ & $\begin{array}{c}\mathrm{K}_{\mathrm{i}} \text { offset } \\
{[\mathrm{p} / \mathrm{km}]}\end{array}$ \\
\hline Euro 4* & $1.3 \times 10^{11}$ & 1000 & $1.3 \times 10^{11}$ & 11.0 & $1.3 \times 10^{11}$ & 1.0 & 0 \\
\hline Euro 5 & $2.0 \times 10^{10}$ & 250 & $2.0 \times 10^{12}$ & 23.2 & $1.9 \times 10^{11}$ & 9.4 & $1.7 \times 10^{11}$ \\
\hline Euro 5 & $2.0 \times 10^{11}$ & 250 & $1.4 \times 10^{12}$ & 11.0 & $2.5 \times 10^{11}$ & 1.3 & $5.1 \times 10^{10}$ \\
\hline Euro 6 & $5.5 \times 10^{9}$ & 300 & $6.9 \times 10^{12}$ & 23.2 & $5.0 \times 10^{11}$ & 91 & $4.9 \times 10^{11}$ \\
\hline Euro 6 & $2.0 \times 10^{10}$ & 800 & $2.0 \times 10^{10}$ & 23.2 & $2.0 \times 10^{10}$ & 1.0 & 0 \\
\hline Euro 6 & $1.0 \times 10^{11}$ & 500 & $4.0 \times 10^{12}$ & 23.2 & $2.7 \times 10^{11}$ & 2.7 & $1.7 \times 10^{11}$ \\
\hline Euro 6 & $2.0 \times 10^{10}$ & 450 & $2.1 \times 10^{11}$ & 11.0 & $2.5 \times 10^{10}$ & 1.2 & $4.5 \times 10^{9}$ \\
\hline Euro 6 & $6.7 \times 10^{10}$ & 450 & $1.9 \times 10^{12}$ & 23.2 & $1.6 \times 10^{11}$ & 2.3 & $9.0 \times 10^{10}$ \\
\hline Euro 6 & $2.7 \times 10^{10}$ & 250 & $7.9 \times 10^{10}$ & 11.0 & $2.9 \times 10^{10}$ & 1.1 & $2.2 \times 10^{9}$ \\
\hline \multicolumn{8}{|c|}{ * Golden PMP vehicle provided by AECC } \\
\hline
\end{tabular}

Table 2. Estimation of $K_{i}$ factors for regeneration [21, 26]. All vehicles equipped with DPF

\subsection{Sub-23 nm instrumentation}

A feasibility study [27] concluded that regulating below $10 \mathrm{~nm}$ is not recommended due to extreme particle losses in the commercial systems at the sub-10 $\mathrm{nm}$ range and the possibility of artefacts (re-nucleation or pyrolysis). For $>10$ $\mathrm{nm}$ measurements, a catalytic stripper and/or high dilutions are recommended in order to reduce the possibility for renucleation and growth of re-nucleated material. Updating existing systems to measure below $23 \mathrm{~nm}$ (e.g. from $10 \mathrm{~nm}$ ) is possible without big investment costs.

After the JRC feasibility study, preliminary draft technical specifications were based on existing PMP systems with the only additions (still draft) [28]:

- PCRF at $15 \mathrm{~nm}$

- CPC with $50 \%$ (or higher) at $10 \mathrm{~nm}$ 
The main open questions are:

- Should the catalytic stripper be obligatory or not? If yes, what are the minimum technical specifications of the catalytic stripper?

- How to take into account the particle losses below 30 $\mathrm{nm}$ ? Is an additional PCRF at e.g. $15 \mathrm{~nm}$ enough? Should the mean PCRF include the $15 \mathrm{~nm}$ point (weighted or not)?

Obviously, in case of lowering the lower detectable size, the material for both PNC and VPR calibration has to be reinvestigated and the calibration procedures need to be updated. Additionally, the SPN-PEMS specifications have to be adjusted accordingly.

Figure 4 presents the penetration curves of two commercial systems (one with evaporation tube [29] and the other with catalytic stripper [30]) and the difference between them when measuring particles of different count median diameters (CMD). The difference becomes important (> 10\%) when the CMD becomes smaller than $30 \mathrm{~nm}$.

In order to avoid uncertainties for size distributions with low CMD or more complicated approaches like in aviation, the easiest way is to include the $10 \mathrm{~nm} \mathrm{CPC}$ in addition to the $23 \mathrm{~nm}$ CPC. This would increase the investment costs of the OEMs, but has the advantage that the $>23 \mathrm{~nm}$ approach could remain and the sub- $23 \mathrm{~nm}$ information could be used separately (e.g. regulating in addition a maximum sub-23 nm fraction or level). With two CPCs the sub-23 nm concentration can be estimated as follows:

(SPN10-SPN23) x PCRF15 / PCRF
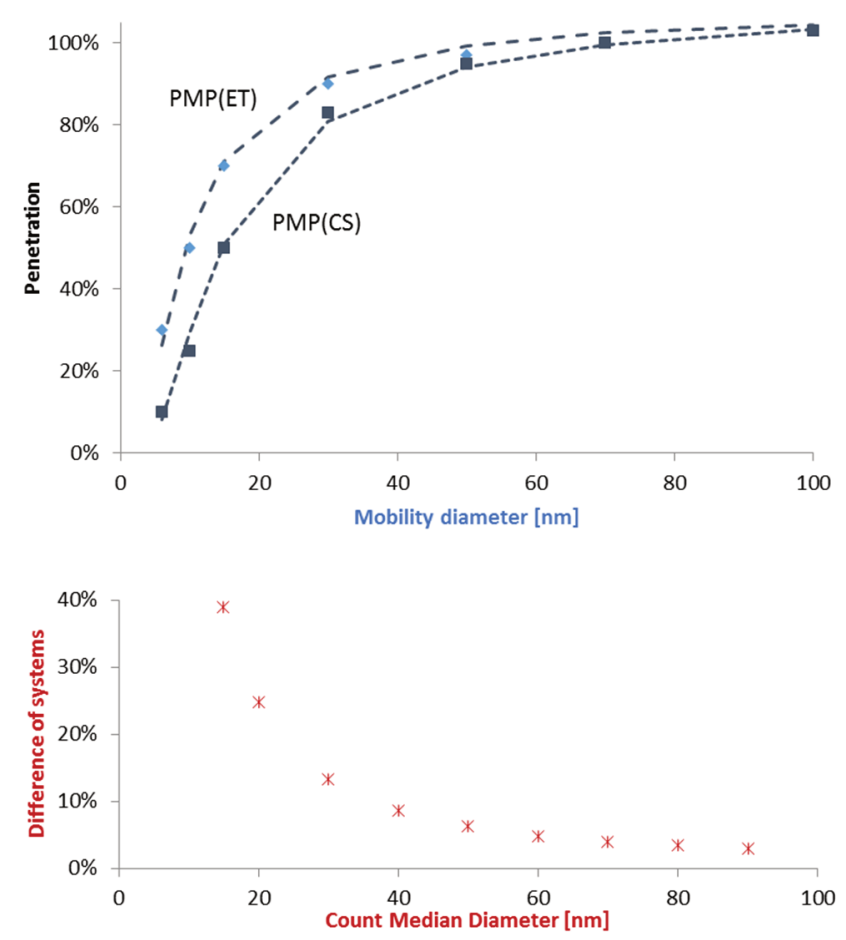

Fig. 4. Upper panel: Counting efficiency in function of monodisperse mobility diameter of two VPRs of PMP systems with Evaporation Tube (ET) [29] or Catalytic stripper (CS) [30] (examples). Lower panel: Difference of the two systems for various polydisperse size distributions with various Count Median Diameters (CMD)

\subsection{Sub-23 nm round robin}

In order to assess the repeatability and reproducibility of the SPN10 (and SPN23) method an inter-laboratory exercise was organised at the end of 2017. Two golden PMP systems (from different manufacturers) measured both from $10 \mathrm{~nm}$ and $23 \mathrm{~nm}$ and were compared with the lab systems measuring from $23 \mathrm{~nm}$ and additionally from 10 with two golden CPCs (from different manufacturers). The golden car was a GDI without particle filter. The testing started at JRC, Italy in October 2017 and the European part finished in June 2018.

The first results are promising and showed similar variability between $10 \mathrm{~nm}$ and $23 \mathrm{~nm}$ CPCs connected to systems with catalytic strippers [31].

\subsection{Sub-23 nm monitoring}

One major task of JRC is to monitor new technologies regarding existence of sub-23 $\mathrm{nm}$ particles. There are various JRC updates on the topic for light-duty [30, 32], L-category [15], heavy-duty [33]. Figure 5 summarises emission levels of various vehicle categories based on a few studies that focused on the most recent technologies: Euro VI heavy-duty vehicles, Euro 5 and Euro 6 light-duty vehicles (cold start included in the test cycle), Euro 2 and Euro 3 mopeds and motorcycles (cold start weighted 30\%). Based on these results the sub-23 nm fractions are:

- 60-100\% for spark ignition engines (natural gas, port fuel injection, mopes and motorcycles)

$-\quad<50 \%$ for diesel engines with or without DPF.

The conclusion of this study is that the solid sub-23 nm fractions can be significant; however, the sub-23 nm absolute emission levels might be low. For example, PFI vehicles are typically below the SPN limit even when including the sub-23 nm fraction. Thus, for regulatory purposes the current methodology still captures high emitters for most of the cases (i.e., a vehicle that passes with the $23 \mathrm{~nm} \mathrm{CPC}$ would also pass with the $10 \mathrm{~nm}$ CPC and vice versa).

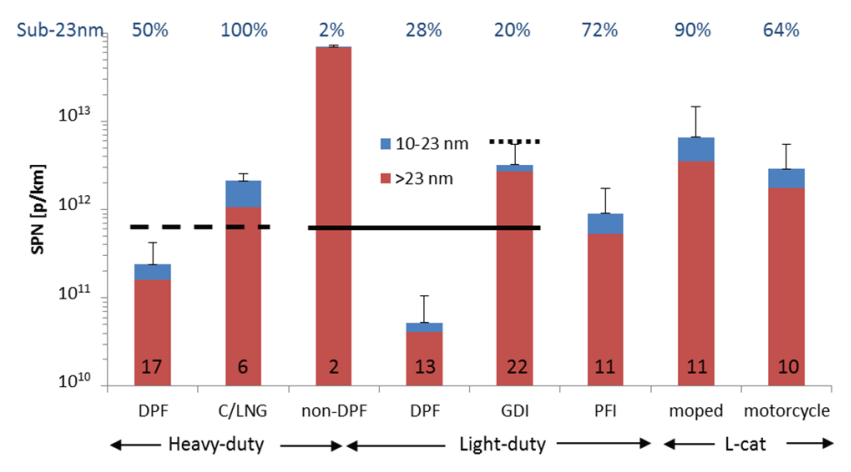

Fig. 5. Overview of emission levels of different current vehicle categories, based on JRC measurements $[15,30,32,33]$. Error bars show one standard deviation (only positive side) for the number of vehicles shown in each bar. Horizontal lines give the European regulated SPN limits for SPN $>23$ $\mathrm{nm}$. Note that for the GDIs of this figure the limit was $6 \times 10^{12} \mathrm{p} / \mathrm{km}$ (dotted line). The dashed line shows a limit of $6 \times 10^{11} \mathrm{p} / \mathrm{km}$. However, the SPN limit applies only to heavy-duty engines (not vehicles) and is expressed in $\mathrm{p} / \mathrm{kWh}$. All tests were conducted at temperatures around $23^{\circ} \mathrm{C}$

\subsection{Low temperatures measurements}

The emissions during low ambient temperatures (Type 6 test) of Regulation 2017/1151 refer to the UNECE Regulation 83. No SPN23 emissions are covered. The topic is 
under discussion for the next revision of WLTP focusing on an engine/vehicle technology independent test procedure covering all pollutants (including SPN23). The PMP contribution was only to ensure that SPN23 are feasible without any particular requirements. The WLTP revised version will require that no condensation takes place until the measurement of the SPN23 (or PM) at $-7^{\circ} \mathrm{C}$.

Figure 6 summarises JRC results of the last years on the topic. The emissions are always higher at lower ambient temperature when there is no particle filter. When there is a particle filter (DPF or GPF) the emissions are usually higher but not always. Nevertheless, in this case, they remain below the $6 \times 10^{11} \mathrm{p} / \mathrm{km}$ limit.
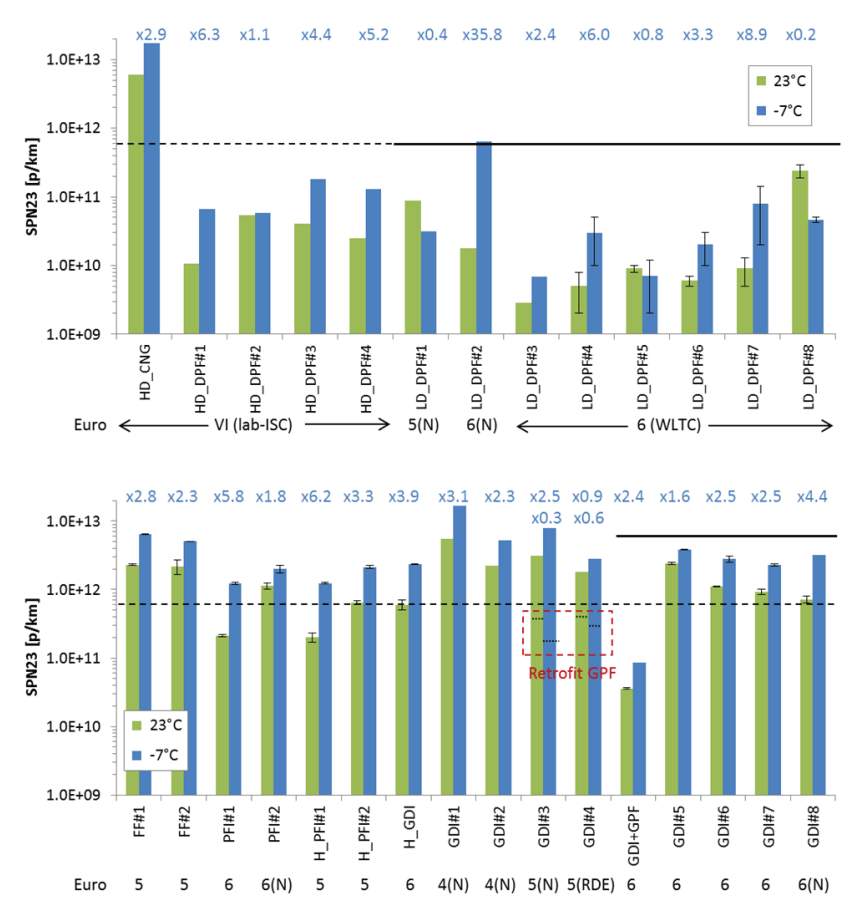

Fig. 6. Emissions from various vehicles at $23^{\circ} \mathrm{C}$ and $-7^{\circ} \mathrm{C}$. Upper panel: Heavy-duty (HD) vehicles and light-duty (LD) diesel vehicles. Lower panel: Gasoline light-duty vehicles. Data from [22, 32-37]. The solid line show the applicable limits of $6 \times 10^{11} \mathrm{p} / \mathrm{km}$ for diesel light-duty vehicles and $6 \times 10^{12} \mathrm{p} / \mathrm{km}$ for GDIs. Dashed lines are aid to the eye. The SPN limit applies only to heavy-duty engines (not vehicles) and is expressed in $\mathrm{p} / \mathrm{kWh}$. "N" for NEDC. Euro level is shown at the lower part of the figures. Ratio of $-7^{\circ} \mathrm{C}$ to $23^{\circ} \mathrm{C} \mathrm{SPN} 23$ emissions is given at the upper part of the figures

\subsection{Raw exhaust sampling via fixed dilution}

For type approval of light-duty vehicles raw exhaust sampling is not allowed. For heavy-duty vehicles proportional partial flow sampling systems are necessary for transient cycles. The reason is that proportional sampling is needed for the filter mass method to be equivalent to the full dilution method. However, the SPN method measures in real time, thus SPN emissions can be calculated if the exhaust flow rate is known. The investigations on the topic will follow these steps:

- Collection of experimental data (comparisons of CVS, partial flow systems and raw exhaust measurements with fixed dilution).

- Theoretical uncertainty analysis.

- Decision on technical specifications, in case raw exhaust sampling is proven to be robust and accurate.
The plan is to start with the heavy-duty evaluation because the conditions there are more extreme compared to light-duty vehicles (exhaust gas temperatures, high bio-fuel content, passive regenerations, pressure pulsations etc.) [38, 39].

Figure 7 summarises the experimental data available in the literature until today. The studies that were found are:

- JRC study with a Euro III engine equipped with different DPFs and a US2007 engine [40].

- PMP Heavy-duty inter-laboratory exercise [41]

- OEMs SPN PEMS validation [12]

- MAN study with a Euro VI diesel and a Euro VI CNG engine [42]

- CUMMINS study with Euro VI engines [43]

- HORIBA study with a DPF equipped engine [44]

- JRC light-duty SPN PEMS study [45]

In general the mean differences between raw exhaust (tailpipe) sampling and CVS or PFDS are within 30\%.

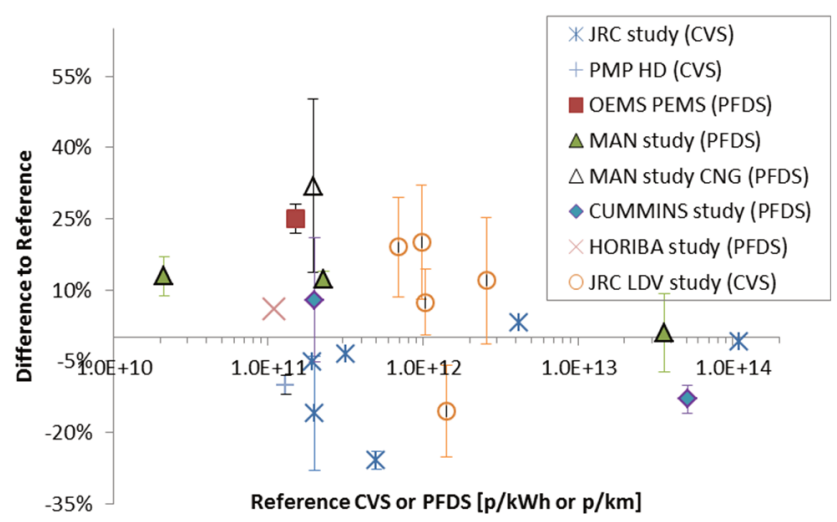

Fig. 7. Differences of SPN23 systems at the tailpipe from SPN23 systems at the CVS or PFDS. Each point is an engine with at least 3 tests. Error bars show one standard deviation of the differences

\section{SPN PEMS}

The interest for developing a procedure for on road testing of light-duty vehicles using Portable Emission Measurement Systems (PEMS) for SPN23 was announced in November 2012. In April 2013 the kick-off meeting took place. The group worked intensively and continuously until the end of 2015 on this issue. This work was independent from PMP activities.

\subsection{Theoretical evaluation}

In a preliminary study [46] a theoretical evaluation was conducted and showed that Diffusion Chargers (DCs) could be an acceptable alternative to CPC-based systems, if an extra uncertainty of around $50 \%$ when compared to CPCs would be acceptable. Based on the findings of that study, the minimum required specifications of the DCs were drafted.

\subsection{JRC experimental evaluation: Phases I and II (light-duty)}

At a next step (end of 2013) various prototype SPN23 PEMS (based on DCs) were evaluated in a chassis dynamometer lab to assess and validate the application and performance of portable SPN23 instrumentation [47]. The systems were measuring from the tailpipe and were compared to reference SPN23 systems (i.e. PMP compatible) at 
the tailpipe and the full dilution tunnel with Constant Volume Sampling (CVS).

The results from three GDIs and one DPF equipped vehicle showed that the best performing SPN-PEMS (DCbased) was up to $100 \%$ higher when compared to the reference system at the dilution tunnel (CVS). Based on the findings of the previous studies, the technical requirements of the SPN-PEMS were drafted.

In the second evaluation Phase (which started in September 2014 and lasted till the end of that year) 8 SPNPEMS (5 of them DC-based) were compared with legislation compliant SPN systems connected to the tailpipe and the dilution tunnel (CVS) [45]. The results of 7 GDIs, 3 PFIs, 2 DPFs, 3 motorcycles and 1 moped, confirmed the findings of Phase I: Diffusion Charging (DC) based systems are a feasible option to measure SPN. The best performing SPN-PEMS (DC-based, the same as in Phase I) had differences from the reference instrument at the dilution tunnel within $50 \%$ (with only a few exceptions).

However, one CPC-based SPN-PEMS, which arrived later in the program, had behaviour equivalent to the reference systems and better real time comparability with the reference systems compared to the DC-based systems. Further evaluation of the system after the campaign with another 10 vehicles confirmed these findings [45]. Based on the experimental data new and stricter efficiencies for SPNPEMS were recommended for the technical requirements in order to reduce the measurement uncertainty of DCs at the CPC levels.

\subsection{Inter-laboratory correlation exercise (light-duty)}

The inter-laboratory exercise, which took place between September 2015 and December 2015 (one more lab measured in May 2016), aimed to assess the accuracy and precision of the method using two different SPN-PEMS (one DC-, and one CPC-based) on one Golden Vehicle in different laboratories across Europe directly involving other stakeholders, such as industry and technical services.

The SPN-PEMS DC-based deviation from PMP-CVS ranged from $-34 \%$ to $53 \%$, while SPN-PEMS CPC-based deviation from PMP-CVS ranged from $-40 \%$ to $46 \%$ [48]. However, it should be noted that the main reason for these deviations was that some of the PMP-CVS systems were overor underestimating (i.e., probably they had calibration issues).

\subsection{JRC experimental evaluation (heavy-duty)}

At the end of September 2015, in a heavy-duty vehicles PEMS meeting, it was decided to evaluate the particle number method, because the filter based PEMS method was not sensitive enough. The kick-off meeting was held in Ispra (Italy) in October of 2015. JRC evaluated some SPN PEMS instruments in the lab and on the road at different ambient temperatures from February until June 2016 [11] and then the commercial instruments in September 2016 [49]. The differences of the SPN-PEMS to the reference system at the dilution tunnel (PMP-CVS) were found within $35-50 \%$ for temperatures $>0{ }^{\circ} \mathrm{C}$ for both DC- and CPCbased systems.

\subsection{OEMs validation exercise}

After the JRC evaluation, the European Automobile Manufacturers Association (ACEA) started the validation phase testing an even wider range of engines and vehicles. One SPN PEMS (CPC-based) instrument was also circulated to all participants to evaluate the measurement uncertainty of the methodology with SPN PEMS. The two CPCbased PEMS had mean differences compared to the reference PMP systems of better than $20 \%$ with a standard deviation of $22 \%$. The two DC-based systems had mean differences of $80 \%$ and decrease to less than $40 \%$ when a PMP correction was applied or if only emission levels $>3 \times 10^{11}$ $\mathrm{p} / \mathrm{kWh}$ were considered [12].

A theoretical study on the maximum expected uncertainty found a margin of around 63\% [50]. Half of this uncertainty comes from the particle detector (33\%) and up to $25 \%$ due to particle losses and dynamics, especially for CNG engines.

Figure 8 summarises, as an example, the results of the CPC-based SPN PEMS for all campaigns.

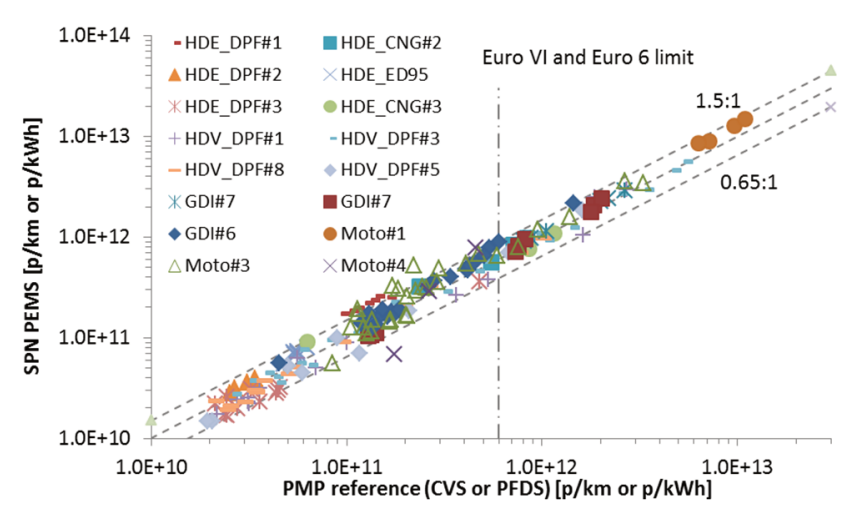

Fig. 8. Summary of L-category, light-duty and heavy-duty results for a CPC-based SPN PEMS compared to reference PMP systems at the full dilution tunnel (CVS) or proportional partial flow dilution systems (PFDS). Each point is a test cycle. Data from [11, 12, 45]

\section{Horizon 2020 projects}

One of the challenges identified in the GV-02-2016 Call 'Technologies for low emission light duty powertrains' was to create opportunities for real breakthrough research by addressing the need of the legislation and automotive industry for a sound metrological base for exhaust particles $<23$ $\mathrm{nm}$ and by supporting the translation of findings into practice. Special attention should be paid on particle emissions of positive ignition engines under real driving conditions, since the emissions measured during the certification process do not always represent these in real world conditions. Three projects focus on the development of measurement systems (DownToTen [51], SUREAL-23 [52], PEMs4Nano [53]) with similar objectives:

- Investigate and quantitatively describe the nature and the characteristics of nanoparticles $<23 \mathrm{~nm}$ (formation, origin, physical and chemical character);

- Develop and set up a synthetic aerosol bench - similar to synthetic exhaust gas bench - and use it for fundamental studies at instrument level. Facilitation of metrology and evaluation purposes;

- Evaluate existing, proposed and under development particle measurement instruments against rigorous criteria for the measurement of the sub $23 \mathrm{~nm}$ particles, with emphasis on the performance within the demanding and hostile environment of PEMS; 
- Analyse exhaustively and compare a large number of possible sampling and sample conditioning configurations (including dilutors, catalytic stripper, evaporation tube, thermodenuder, Constant Volume Sampling (CVS)). Benchmark them against a well-defined set of criteria (incl. losses, efficiencies, uncertainty, repeatability, reproducibility, robustness etc.) and under varying conditions of challenging aerosol from a variety of sources. Select the most promising combinations for further usage;

- Set-up an appropriate Particle Number - PEMS demonstrator that will materialise the findings and suggestions with respect to PN detection and sampling and conditioning;

- Use the above to measure a number of current and future engine and vehicle technologies as well as state-ofthe-art exhaust aftertreatment systems in the laboratory and in real world conditions.

- Develop and propose an appropriate sampling and measurement methodology for the sub $23 \mathrm{~nm}$ particles both in the laboratory and real driving conditions to be employed during engine and vehicle type approval.

The progress of the projects is presented at the PMP meetings since October 2016.

\section{New Periodical Technical Inspection (NPTI)}

An initiative of VERT, launched in November 2016, addresses the needs of tamper-proof methods for exhaust assessment [54]. The initiative focuses on "New periodic technical inspection" (NPTI). The initiative is supported by the European Union as well as the governments of Germany, the Netherlands, Belgium, and Switzerland. The VERT/TNO NPTI proposal with the particle number test in idle run for diesel vehicles is summarised in a White Paper [55]. It is assumed that the process will be suitable with minor if any modifications also for petrol engines. The instrumentation is still under development. The first results are promising. Instruments in their prototype stage are already capable of recognizing vehicles that have been manipulated using partial bypass that resulted in SPN23 emissions close to maximum allow type approval levels (i.e. $6 \times 10^{11} \mathrm{p} / \mathrm{km}$ ) (see Fig. 9) and present a satisfactory correlation with SPN PEMS compliant instrumentation. Work on the testing procedure and pass/fail limit is still on going. This work is also under the evaluation of the Roadworthiness Technical Working Group which focuses on the roadworthiness aspects of tampering with exhaust emission control systems.

In September 2017 the Federal Council in Germany passed a law which demands periodical technical inspection of tailpipe emission applicable since January 2018 for gaseous pollutants (but currently no $\mathrm{NO}_{\mathrm{x}}$ ) and from January 2019 for particles.

Figure 9 summarizes the results from different studies:

- TNO study at low idle with three vehicles [56]

- JRC NPTI instruments pre-evaluation with one DPF equipped vehicle with bypass at low idle [57]

- SPN-PEMS evaluation study using idle data of the NEDC and WLTC [45].
The results show a medium correlation between emission levels during type approval cycle (NEDC or WLTC) and low idle emissions even with SPN-PEMS instruments. The scatter further increases when first generation NPTI instruments are included. Any low idle limit has to take into account this scatter, but the technical specifications of NPTI instruments should have acceptable uncertainty, with low cost.

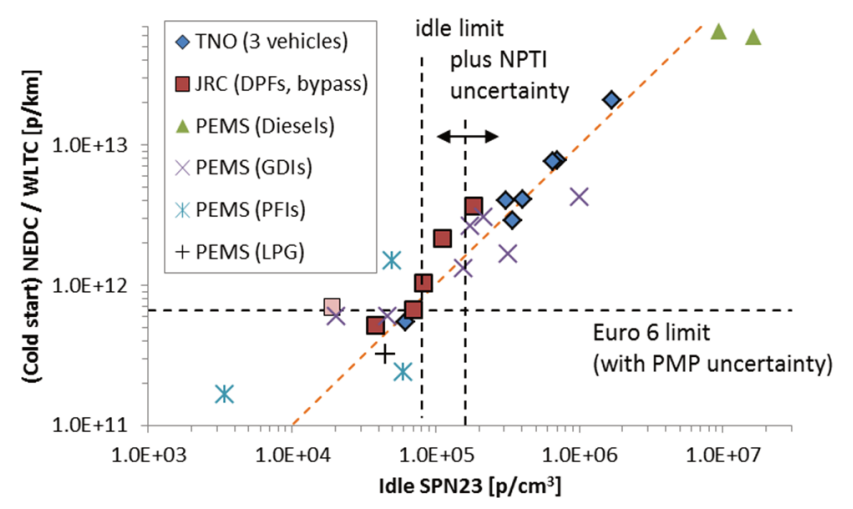

Fig. 9. Emission factor $(\# / \mathrm{km})$ during NEDC or WLTC vs raw exhaust concentration $\left(\# / \mathrm{cm}^{3}\right)$ measured during low idle with different PMP or SPN-PEMS instruments based on the PEMS project (Chapter 4). TNO data from [56]. JRC data and NPTI uncertainty estimation from [57]

\section{Market surveillance}

After the VW scandal a European Type Approval Authorities Experts Group (TAAEG) was set [58, 59] to ensure uniform application of the requirements for motor vehicles within the Community type-approval system, and to facilitate the exchange of information and experience regarding the implementation of type-approval legislation for vehicles. From the discussions of this group and with the contribution of the JRC, the Commission has published a guidance note to evaluate emissions strategies and to detect the presence of defeat device [60]. From this guidance, several requirements were included in the RDE regulation, with for instance the requirement of the manufacturer to provide to the Granding Type approval Authorities (GTAA) the extended documentation describing the auxiliary emission strategy of its vehicle (included in RDE $3^{\text {rd }}$ package). Additionally, this guidance defined the requirements for an efficient in-service conformity checking, many of which have been included in the RDE 4, voted in May 2018.

In parallel, a revision of the EU type-approval framework was voted in 19 April 2019 that will replace Directive 2007/46/EC. Member states will be able to take measures (including ordering vehicle recalls and revoking typeapproval certificates) against non-compliant vehicles sold in their national markets, instead of having to wait for the type-approval authority of the country that issued the vehicles' type-approval certificate to take action. The new typeapproval framework introduces also an effective market surveillance system to control the conformity of vehicles already in circulation. The new Regulation for typeapproval and market surveillance of motor vehicles will enter into force on September 2020, and the first in-service conformity testing in September 2019. While the focus is mostly $\mathrm{NO}_{\mathrm{x}}$ and $\mathrm{CO}_{2}$, SPN is also being checked through 
this new in service conformity process, as all the regulated pollutants.

\section{Non-exhaust particle emissions}

There is currently no regulation related to brakes particle emissions neither in Europe nor in any other part of the world [61]. This is due to several reasons with the most important being the lack of accurate scientific data on the relative contribution of brake wear particles to overall PM10 pollution, the inaccurate - and sometimes outdated brake wear PM10 and PM2.5 emission factors reported in the literature as well as the lack of health studies directly linking brake wear particles to adverse health effects [62]. The PMP group is currently working on the development of a standardized test procedure for sampling, measurement and characterization of brake wear particles. The main goal of the methodology is to provide researchers and interested parties with a commonly accepted procedure for assessing real-world brake particle emissions. The first step of the procedure includes the development of a real-world braking test cycle. Real world PM and PN emission factors can be reported only if real world driving and braking conditions are examined. The analysis of the WLTP database showed that in many cases the driving conditions applied by researchers to study brake wear emissions were substantially different from real world driving and braking situations [63]. Further comparison of real-world driving and braking data with existing industrial braking cycles showed that the latest are very aggressive and in any case not representative of real world conditions [64]. For all these reasons it was decided to go towards the development of a completely new real-world braking test schedule. At the same time, the PMP is working on the development of a suitable methodology for sampling brake wear particles as well as on selecting the most suitable existing methods for brake wear particles' measurement and characterization. For that reason, a dedicated Task Force has been created within the PMP with the aim of accelerating the work [65]. The focus of the Task Force is on developing a methodology suitable for PM and PN concentration measurement. This is necessary as there is a great diversity among the published results. The Task Force includes representatives from the brake industry, OEMs, instrument manufacturers, regulatory bodies and universities/research institutes thus ensuring a holistic as well as a thorough technical support. The cycle was circulated through the PMP website in July 2018 and the goal is to deliver the proposed methodology by the end of the current mandate in June 2019. Figure 10 presents some PM mass and SPN results. Although the PM mass emissions over WLTCs can exceed the vehicle exhaust PM limit, the SPN emissions are very low.

Regarding tyre wear particles there is no regulation related to its particle emissions neither in Europe nor in any other part of the world [61]. Except for the reasons listed above and which also apply to tyre wear particle emissions, there is the issue of the direct dependence of tyre wear emissions to the type of road/pavement which makes it more difficult to regulate [68]. The PMP communicated the difficulties to the GRPE and made clear that a full scale investigation of the tyre related open issues would require a time and resource consuming large scale experimental project. Neither the PMP, nor the JRC, had the necessary resources to perform such an experimental project. The GRPE decided to continue monitoring on-going projects and published data regarding the physical nature and size distribution of particle emissions from tyre wear and committed to eventually provide a report to GRPE on the investigation status and recommended next steps. In the meantime, JRC decided to perform a joint study with the Swedish National Road and Transport Research Institute (VTI) with the aim of exploring whether there is a relation between the Treadwear Rating (TWR) declared by the manufacturers at the sidewall of the summer tyres and the tread mass loss of the tyre. The relation between the TWR and the generation of tyre wear dust in the form of PM10, PM2.5 and (S)PN concentration were also explored. The results of this study have been presented at the $47^{\text {th }}$ PMP Meeting and will serve as a starting point for the discussion which will follow in order to come up with a recommendation for the next steps. The initial idea is to bring to the GRPE the need for the development of a standardized methodology for measuring the abrasion of the tyres. Such a methodology would give the opportunity to study not only tyre wear particle emissions but also emissions of other pollutants (i.e. microplastics).

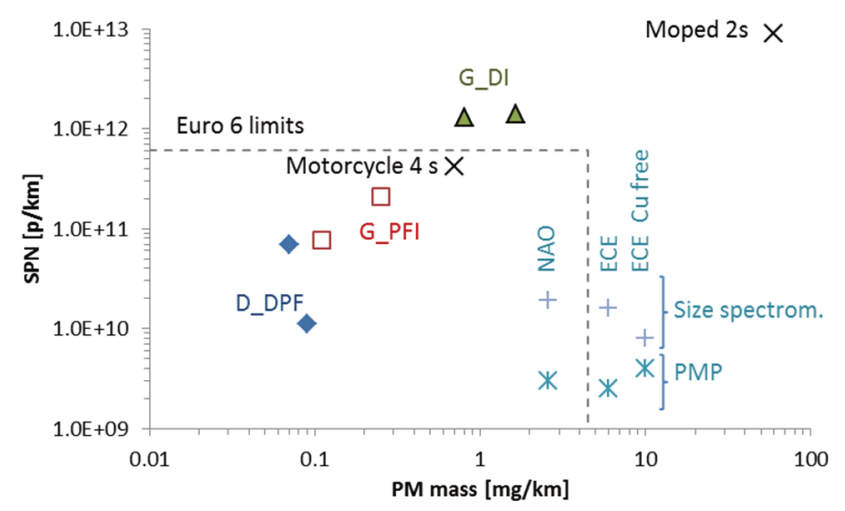

Fig. 10. PM mass and SPN measurements from a dilution tunnel using series-production pads from European market (ECE) and of non-asbestos organic (NAO) type (US market) with or without copper (Cu free). Results from $[66,67]$. Results from exhaust emissions of various vehicles is also given for comparison [30]

\section{Next steps: Post Euro VI and Euro 6}

The major issues the last years were the development of more representative test cycles and procedures (WLTP) and on-road testing of vehicles. Even though RDE and WLTP were introduced, many other challenges lay ahead: Increased use of alternative fuels, electrification, the use of new technologies, increasing connectivity and automation and the advancement of measurement techniques, raise the need to evaluate what pollutants should be regulated in the future and how. Some of the main issues to be addressed, and closely related to SPN emissions, are:

- Review of the existing emission limits: Is there a need for a further reduction?

- Unregulated pollutants, including lower detected particle size.

- Full exploitation of on-board diagnostics and on-board monitors. 
- Review of all existing tests (necessity, international harmonisation).

- Review of test cycles (mostly relevant for NRMM).

- Durability requirements review.

- Anti-tampering protection (especially at software level).

- Non-exhaust emissions.

- Interior vehicle air quality.

- Harmonization of regulations.

However, it is too early to foresee any directions, because it is still brainstorming and collection of input period.

\section{Conclusions}

The European vehicle emissions regulation includes a solid particle number $>23 \mathrm{~nm}$ (SPN23) limit for lightduty, heavy-duty on-road, and non-road mobile machinery (NRMM). For L-category vehicles at the moment the SPN emissions are being monitored by JRC.

In-Service Conformity testing includes SPN measurements with Portable Emissions measurement Systems (PEMS) for light-duty and heavy-duty vehicles. The additional uncertainty of SPN23 PEMS is covered with a socalled Conformity Factor (CF) that includes a margin for the instrument uncertainty. The uncertainty was based on theoretical and experimental evaluation at JRC and other laboratories.

The main topics that are under discussion at the moment are:

Calibration procedures: Some requirements that can be narrowed have been identified for both VPR and CPC calibrations. A very important finding is that soot-like aerosol is a suitable candidate for CPC calibration harmonizing the material for the various applications (VPR, CPC, PEMS).

Regeneration: The investigations confirmed that PMP systems can be used without any artefact issues during regeneration events of light-duty vehicles. Today there are no particular concerns that including the $\mathrm{K}_{\mathrm{i}}$ factor will result in high emissions for DPF equipped vehicles. However this will be important if the emission limit is decreased.

Sub-23 nm feasibility: The feasibility study summarised that lowering the current lowest detectable size of $23 \mathrm{~nm}$ down to $10 \mathrm{~nm}$ is possible without large investment costs. An inter-laboratory exercise with prototype systems is currently on-going to confirm the theoretical assumptions. The two main open questions are 1) whether a catalytic stripper should be obligatory or not, and its specifications, and 2) how to take into account the losses at the sub- $23 \mathrm{~nm}$ range. A simple solution could be to leave the PCRF as it is today. A more accurate solution is adding a $10 \mathrm{~nm} \mathrm{CPC} \mathrm{to}$ the existing $23 \mathrm{~nm}$ CPC. However the feasibility of such solution for regulatory purposes has to be discussed.

Sub-23 nm monitoring: The sub-23 nm fraction is relatively high for spark-ignition engines exceeding $60 \%$. However, at the moment the $23 \mathrm{~nm}$ lower detectable size captures the majority of vehicles exceeding the legislation limit.

Low temperatures testing: The testing is possible. At $-7^{\circ} \mathrm{C}$ the emissions increase by a factor of $>2$ in most cases without a particle filter.

Raw exhaust sampling: Preliminary literature overview showed that raw exhaust systems are within $30 \%$ of regulated systems. A more detailed experimental investigation is foreseen in the near future.

$S P N-P E M S$ : The experimental uncertainty of the systems (plus the raw exhaust sampling) is around 50-60\% today. Next steps include extension of PEMS testing to regulations that have a SPN laboratory limit (e.g. heavyduty engines and NRMM).

NPTI: The on-going activities regarding new periodical technical inspection for particle number are promising. It seems feasible to measure at idle with sensors and identify a mal-functioning DPF. The technical specifications are being drafted and extension to gasoline engines is undergoing.

Non-exhaust emissions: A test cycle has been prepared for brake wear emissions and the sampling methodology is under discussion. Tyre wear emissions will be investigated in more details the future.

\section{Acknowledgments}

The authors would like to thank the VELA laboratory staff for their experimental support for all above mentioned activities.

\section{Funding}

This research did not receive any specific grant from funding agencies in the public, commercial, or not-for-profit sectors.

\section{Conflicts of Interest}

The authors declare no conflict of interest.

\section{Disclaimer}

The opinions expressed in this manuscript are those of the authors and should in no way be considered to represent an official opinion of the European Commission. Mention of trade names or commercial products does not constitute endorsement or recommendation by the authors.

\section{Nomenclature}

ACEA Association for Emissions Control by Catalyst

CAST Combustion Aerosol Standard

CF Conformity Factor

CMD Count Median Diameter

CNG Compressed Natural Gas

CPC Condensation Particle Counter

CS Catalytic Stripper

CVS Constant Volume Sampler

DC Diffusion Charger

DPF Diesel Particulate Filer
ED95 95\% Ethanol fuel

EEPS Engine Exhaust Particle Sizer

ET Evaporation Tube

EU European Union

GDI Gasoline direct Injection

GRPE Working Party on Pollution and Energy

GSD Geometric Standard Deviation

GTR Global Technical Regulation

HD Heavy-Duty

HDE Heavy-Duty Engine 


$\begin{array}{ll}\text { HDV } & \text { Heavy-Duty Vehicle } \\ \text { ISC } & \text { In-Service Conformity } \\ \text { JRC } & \text { Joint Research Centre } \\ \text { LD } & \text { Light-Duty } \\ \text { NEDC } & \text { New European Driving Cycle } \\ \text { NPTI } & \text { New periodic Technical Inspection } \\ \text { NRMM } & \text { Non-Road Mobile Machinery } \\ \text { NRSC } & \text { Non-Road Steady Cycle } \\ \text { NRTC } & \text { Non-Road Transient Cycle } \\ \text { OBD } & \text { On-Board Diagnostics } \\ \text { OEM } & \text { Original Equipment Manufacturer } \\ \text { PCRF } & \text { Particle number Concentration Reduction Factor } \\ \text { PEMS } & \text { Portable Emissions Measurement System } \\ \text { PFDS } & \text { Proportional partial Flow Dilution System } \\ \text { PFI } & \text { Port Fuel Injection } \\ \text { PM } & \text { Particulate Matter } \\ \text { PMP } & \text { Particle Measurement Programme }\end{array}$

\author{
PN Particle Number \\ PTI Periodic Technical Inspection \\ RDE Real-Driving Emissions \\ SPN Solid Particle Number \\ TAAEG Type Approval Authorities Experts Group \\ TWR Treadwear Rating \\ UN United Nations
}

UNECE United Nations' Economic Commission for Europe

VERT Verification of Emission Reduction Technologies

VPR Volatile Particle Remover

WHSC Worldwide Harmonized Stationary Cycle

WHTC Worldwide Harmonized Transient Cycle

WLTC Worldwide harmonized Light-Duty Transient Cycle

WLTP Worldwide harmonized Light-Duty Test Procedure WMTC Worldwide harmonized Motorcycle Transient Cycle

\section{Bibliography}

[1] World Health Organization. Review of evidence on health aspects of air pollution-REVIHAAP Project; WHO Regional Office for Europe: Copenhagen, Denmark, 2013.

[2] KUMAR, P., MORAWSKA, L., BIRMILI, W. et al. Ultrafine particles in cities. Environment International. 2014, 66, $1-10$.

[3] Report of the GRPE Particle Measurement Programme (PMP): Government Sponsored Work Programmes, Available at: https://www.unece.org/fileadmin/DAM/trans/doc/2003/ wp29grpe/TRANS-WP29-GRPE-specinf01e.pdf

[4] GIECHASKIEL, B., MAMAKOS, A., ANDERSSON, J. et al. Measurement of automotive nonvolatile particle number emissions within the European legislative framework: a review. Aerosol Science and Technology. 2012, 46, 719-749.

[5] PMP-27-02 Draft Proposal for UNECE GRPE PMP ToR_24_04_2013. (Final at PMP 41). https://wiki.unece. org/display/trans/PMP+27th+session

[6] BISCHOF, O. Recent developments in the measurement of low particulate emissions from mobile sources: a review of particle number legislations. Emission Control Science and Technology. 2015, 1, 203-2212.

[7] GIECHASKIEL, B., MARICQ, M., NTZIACHRISTOS, L. et al. Review of motor vehicle particulate emissions sampling and measurement: from smoke and filter mass to particle number. Journal of Aerosol Science. 2014, 67, 48-86.

[8] OTSUKI, Y., NAKAMURA, H., ARAI, M., XU, M. The methodologies and instruments of vehicle particulate emission measurement for current and future legislative regulations. Measurement Science and Technology. 2015, 26, 092002.

[9] GIECHASKIEL, B., CLAIROTTE, M., VALVERDE-MORALES, V. et al. Framework for the assessment of PEMS (Portable Emissions Measurement Systems) uncertainty. Environmental Research. 2018, 166, 251-260.

[10] MAMAKOS, A., BONNEL P., PERUJO A., CARRIERO, M. Assessment of portable emission measurement systems (PEMS) for heavy-duty diesel engines with respect to particulate matter. Journal of Aerosol Science. 2013, 57, 54-70.

[11] GIECHASKIEL, B., RICCOBONO, F., MENDOZA, P., GRIGORATOS, T. Particle Number (PN) - Portable Emissions Measurement Systems (PEMS): Heavy Duty Vehicles Evaluation Phase at the Joint Research Centre (JRC). JRC scientific report EUR $28256 \mathrm{EN}, 2016$.

[12] GIECHASKIEL, B., SCHWELBERGER, M., DELACROIX, C. et al. Experimental assessment of solid particle number
Portable Emissions Measurement Systems (PEMS) for heavy-duty vehicles applications. Journal of Aerosol Science. 2018, 123, 161-170.

[13] ZARDINI, A., CLAIROTTE, M., LANAPPE, G. et al. Preparatory work for the environmental effect study on the Euro 5 step of L-category vehicles. European Commission Joint Research Centre Science for Policy Report JRC100557; EUR 27788 EN, 2016.

[14] CLAIROTTE, M., ZARDINI, A., MARTINI, G. Phase 1 of the environmental effect study on the Euro 5 step of Lcategory vehicles - Stocktaking and data mining, European Commission JRC Scientific and Technical Research Reports, EUR 27994 EN, 2016.

[15] GIECHASKIEL, B., ZARDINI, A., MARTINI, G. Particle emission measurements from L-category vehicles. SAE International Journal of Engines. 2015, 8(5), 2322-2337.

[16] TNO Report for European Commission, Directorate-General for Internal Market, Industry, Entrepreneurship and SMEs. Effect study of the environmental step Euro 5 for L-category vehicles. ISBN number: 978-92-79-70203-7 doi:10.2873/ 397876. TNO 2017 R10565.

[17] MAMAKOS, A. Particle measurement programme volatile particle remover calibration round robin. Report EUR 25512 EN, 2012.

[18] PMP 36-03 Calibration questionnaire with answers. https://wiki.unece.org/display/trans/PMP+36th+session

[19] GIECHASKIEL, B., WANG, X., HORN, H. et al. Calibration of condensation particle counters for legislated vehicle number emission measurements. Aerosol Science and Technology. 2009, 43, 1164-1173.

[20] TERRES, A., EBERT, V., NOWAK, A. et al. Particle measurement project. inter-laboratory correlation exercise with condensation particle counters. EU report 29277, 2018.

[21] ANDERSSON, J., GIECHASKIEL, B., MUNOZ-BUENO, R., DILARA, P. Particle measurement programme (PMP) light-duty interlaboratory correlation exercise (ILCE_LD). EU Report No. EUR 22775 EN, 2007.

[22] MAMAKOS, A., MARTINI, G., MANFREDI, U. Assessment of the legislated particle number measurement procedure for a Euro 5 and Euro 6 compliant diesel passenger cars under regulated and unregulated conditions. Journal of Aerosol Science. 2013, 55, 31-47.

[23] PMP-30-07 PN \& regeneration. https://wiki.unece.org/ display/trans/PMP+30th+session 
[24] YAMADA, H., FUNATO, K., SAKURAI, H. Application of the PMP methodology to the measurement of sub- $23 \mathrm{~nm}$ solid particles: calibration procedures, experimental uncertainties, and data correction methods. Journal of Aerosol Science. 2015, 88, 58-71.

[25] PMP-37-03_JRC exhaust particles work items status. https://wiki.unece.org/display/trans/PMP+37th+Session

[26] PMP-30-03 Regeneration topics. https://wiki.unece.org/ display/trans/PMP+30th+session

[27] GIECHASKIEL, B., MARTINI, G. Engine exhaust solid sub-23 nm particles: II. feasibility study for particle number measurement systems. SAE International Journal of Fuels and Lubricants. 2014, 7, 935-949.

[28] GRPE-PMP-41-02 JRC_PMP_20161012_v2. https://wiki. unece.org/display/trans/PMP+41st+session

[29] OTSUKI, Y., TAKEDA, K., HARUTA, K., MORI, N. A solid particle number measurement system including nanoparticles smaller than 23 nanometers. SAE Technical Paper. 2014-01-1604, 2014.

[30] GIECHASKIEL, B., VANHANEN, J., VÄKEVÄ, M., MARTINI, G. Investigation of vehicle exhaust sub-23 nm particle emissions. Aerosol Science and Technology. 2017, 51, 626-641.

[31] PMP-47-09 Light Duty-exhaust-sub23_RR_TL_JRC. https://wiki.unece.org/display/trans/PMP+47th+session

[32] GIECHASKIEL, B., MANFREDI, U., MARTINI, G. Engine exhaust solid sub-23 nm particles: I. literature survey. SAE International Journal of Fuels and Lubricants. 2014, 7, 950-964.

[33] GIECHASKIEL, B. Solid particle number emission factors of Euro VI heavy-duty vehicles on the road and in the laboratory. International Journal of Environmental Research and Public Health. 2018, 15, 304.

[34] GIECHASKIEL, B., RICCOBONO, F., VLACHOS, T. et al. Vehicle emission factors of solid nanoparticles in the laboratory and on the road using portable emission measurement systems (PEMS). Frontiers in Environmental Science. 2015, 3

[35] MAMAKOS, A., MARTINI, G., MAROTTA, A., MANFREDI, U. Assessment of different technical options in reducing particle emissions from gasoline direct injection vehicles. Journal of Aerosol Science. 2013, 63, 115-125.

[36] DEMUYNCK, J., FAVRE, C., BOSTEELS, D. et al. Realworld emissions measurements of a gasoline direct injection vehicle without and with a gasoline particulate filter. $S A E$ Technical Paper 2017-01-0985, 2017.

[37] SUAREZ-BERTOA, R., ASTORGA, C. Impact of cold temperature on Euro 6 passenger car emissions. Environmental Pollution. 2018, 234, 318-329.

[38] PMP-37-02 Raw Exhaust PN Counting - Research Areas. https://wiki.unece.org/display/trans/PMP+37th+Session

[39] PMP-47-07 Raw Exhaust via Fixed Dilution. https://wiki.unece.org/display/trans/PMP+47th+session

[40] GIECHASKIEL, B., CARRIERO, M., MARTINI, G. et al. Comparison of particle number measurements from the full dilution tunnel, the tailpipe and two partial flow systems. SAE Technical Paper 2010-01-1299, 2010.

[41] ANDERSSON, J., MAMAKOS, T., GIECHASKIEL, B. et al. Particle Measurement Programme (PMP) Heavy-Duty Inter-Laboratory Correlation Exercise (ILCE HD) Final Report EUR $24561 \mathrm{EN}, 2010$.

[42] BECK, H. Particle number measurement according to PMP protocol and direct measurement. 20th ETH Conference on Combustion Generated Particles. 13-16 June 2016, Zurich, Switzerland.

[43] KHAN, Y., SHARMA, S., LIEW, C. et al. Comparison of full flow dilution, partial flow dilution, and raw exhaust par- ticle number measurements. Emission Control Science and Technology. 2018. DOI:10.1007/s40825-018-0086-6.

[44] PMP-35-08 Direct PN Measurement 4-3-2015. https://wiki.unece.org/display/trans/PMP+35th+session

[45] GIECHASKIEL, B., RICCOBONO, F., BONNEL, P. Feasibility study on the extension of the real driving emissions (RDE) procedure to particle number $(\mathrm{PN})$ : chassis dynamometer evaluation of portable emission measurement systems (PEMS) to measure particle number (PN) concentration: Phase II. JRC report, Ispra, Italy. ISBN 978-92-7951003-8, 2015.

[46] GIECHASKIEL, B., RICCOBONO, F., BONNEL, P. Feasibility study on the extension of the Real Driving Emissions (RDE) procedure to Particle Number (PN): Experimental evaluation of portable emission measurement systems (PEMS) with diffusion chargers (DCs) to measure particle number (PN) concentration; JRC report 26997 EN, 2014.

[47] RICCOBONO, F., GIECHASKIEL, B., WEISS, M., BONNEL, P. How to extend the real drive emission test procedure to particle number. Presentation at the 18th ETH Conference on Combustion Generated Nanoparticles. 25th June 2014, Zurich, Switzerland.

[48] RICCOBONO, F., GIECHASKIEL, B., MENDOZA, P. Particle number PEMS inter-laboratory comparison exercise: performance of PN-PEMS for the extension of the RDE test procedure to PN. EU report $28136 \mathrm{EN}, 2016$.

[49] SCHWELBERGER, M., GIECHASKIEL, B. Evaluation of portable number emission systems for heavy-duty applications under steady state and transient vehicle operation conditions on a chassis dynamometer. SAE Technical Paper 2018-01-0348, 2018.

[50] GIECHASKIEL, B. PN-PEMS theoretical uncertainty evaluation. Presentation to the PEMS expert group, 24 May 2018, Brussels, Belgium.

[51] https://ec.europa.eu/inea/en/horizon-2020/projects/h2020transport/green-vehicles/downtoten

[52] https://ec.europa.eu/inea/en/horizon-2020/projects/h2020transport/green-vehicles/sureal-23

[53] https://ec.europa.eu/inea/en/horizon-2020/projects/h2020transport/green-vehicles/pems4nano

[54] VERT: https://www.vert-dpf.eu/j3/index.php/projects/npti

[55] KADIJK, G., MAYER, A. White paper. NPTI-the New Periodic Technical Inspection emission test procedure for vehicles with emission control systems. 20 June 2017.

[56] KADIJK, G., ELSTGEEST, M., LIGTERINK, N., van der MARK, P. Investigation into a Periodic Technical Inspection (PTI) test method to check for presence and proper functioning of diesel particulate filters in light-duty diesel vehicles - part 2. TNO 2017 R10530, 2017.

[57] SUAREZ-BERTOA, R., LAHDE, T., GIECHASKIEL, B. Verification of NPTI instruments for diesel and petrol vehicles - first results. ETH conference, June 21st 2018, Zurich, Switzerland.

[58] TAAEG available at: http://ec.europa.eu/transparency/ regexpert/index.cfm?do=groupDetail.groupDetail\&groupID $=2403 \&$ NewSearch $=1 \&$ NewSearch $=1$

[59] Regulation of the European Parliament and of the Council on the approval and market surveillance of motor vehicles and their trailers, and of systems, components and separate technical units intended for such vehicles. Brussels, 27.1.2016, $\operatorname{COM(2016)~} 31$ final.

[60] European Commission, COMMISSION NOTICE of 26.1.2017 - Guidance on the evaluation of Auxiliary Emission Strategies and the presence of Defeat Devices with regard to the application of Regulation (EC) No 715/2007 on type approval of motor vehicles with respect to emissions 
from light passenger and commercial vehicles (Euro 5 and Euro 6), 2017, 1-18.

[61] GRIGORATOS, T. Chapter 4 - Regulation on brake/tire composition. Non-exhaust emissions: an urban air quality problem for public health. impact and mitigation measures 2018 Elsevier Inc.

[62] GRIGORATOS, T., MARTINI, G. Brake wear particle emissions: a review. Environmental Science and Pollution Research. 2015, 22, 2491-2504.

[63] PMP-39-04 NEPE - Summary Results of WI-1. https://wiki.unece.org/display/trans/PMP+39th+session

[64] PMP-41-12 Comparison WLTP and Industrial Cycles. https://wiki.unece.org/display/trans/PMP+41st+session

\begin{abstract}
Barouch Giechaskiel, PhD - Scientific Laboratory Manager - JRC, Directorate C - Energy, Transport and Climate, Sustainable Transport Unit, Ispra, Italy.

e-mail: Barouch.Giechaskiel@ec.europa.eu
\end{abstract}

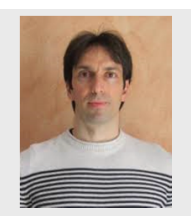

Ricardo Suarez-Bertoa, PhD - Scientific/Technical Project Officer - JRC, Directorate C - Energy, Transport and Climate, Sustainable Transport Unit, Ispra, Italy.

e-mail: Ricardo.Suarez-Bertoa@ec.europa.eu

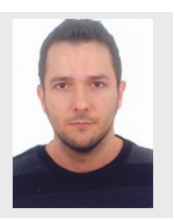

Theodoros Grigoratos, PhD - Scientific/Technical Project Officer - JRC, Directorate C - Energy, Transport and Climate, Sustainable Transport Unit, Ispra, Italy.

e-mail: Theodoros.Grigoratos@ec.europa.eu

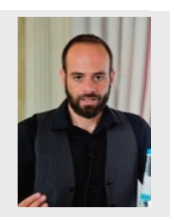

Adolfo Perujo, PhD - Scientific/Technical Project Officer - JRC, Directorate C - Energy, Transport and Climate, Sustainable Transport Unit, Ispra, Italy.

e-mail: Adolfo.Perujo@ec.europa.eu
[65] PMP-45-03 PMP Task Force 11 - brake sampling \& measurement. https://wiki.unece.org/display/trans/PMP+45th+ Session

[66] PMP-45-13 AVL_TUI_particle emissions From_Different_ Types_Of_Break_Pads. https://wiki.unece.org/display/trans/ $\mathrm{PMP}+45 \mathrm{th}+$ Session

[67] PMP-47-16 AVL_TUI_PM_Results. https://wiki.unece.org/ display/trans/PMP+47th+session

[68] GRIGORATOS, T., GUSTAFSSON, M., ERIKSSON, O., MARTINI, G. Experimental investigation of tread wear and particle emission from tyres with different treadwear marking. Atmospheric Environment. 2018, 182, 200-212.

Tero Lahde, $\mathrm{PhD}$ - Scientific/Technical Project Officer - JRC, Directorate C - Energy, Transport, and Climate, Sustainable Transport Unit, Ispra, Italy.

e-mail:Tero.Lahde@ec.europa.eu

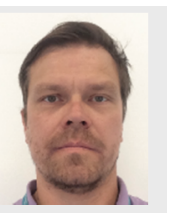

Michael Clairotte, PhD - Scientific/Technical Project Officer - JRC, Directorate C - Energy, Transport, and Climate, Sustainable Transport Unit, Ispra, Italy.

e-mail: Michael.Clairotte@ec.europa.eu

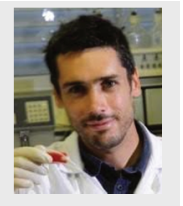

Alessandro Zardini, PhD - Scientific/Technical Project Officer - JRC, Directorate C - Energy, Transport and Climate, Sustainable Transport Unit, Ispra, Italy.

e-mail: Alessandro.Zardini@ec.europa.eu

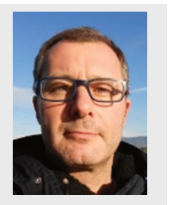

Giorgio Martini - Deputy Head of Unit - JRC, Directorate C - Energy, Transport and Climate, Sustainable Transport Unit, Ispra, Italy.

e-mail: Giorgio.Martini@ec.europa.eu 